\title{
Comunicação e educação: implicações contemporâneas ${ }^{*}$
}

Adilson Citelli*

Professor titular do Departamento de Comunicações e Artes da ECA/USP, onde ministra cursos de graduação e pós-graduação. Orienta dissertações e teses nas áreas de Comunicação e Linguagem, com ênfase nas subáreas Comunicação/Educação, Comunicação/Linguagem. É coeditor da revista Comunicação \& Educação, bem como pesquisador $1 C$ do CNPq. E-mail: citelli@uol.com.br

Resumo: Com este texto prosseguimos na sistematização e difusão de novos dados recolhidos em pesquisa que realizamos entre 2006 e 2009 com professores do Ensino Fundamental e Médio da rede pública municipal e estadual de São Paulo. Procura-se, agora, indagar acerca de tensões que regem as relações entre as práticas profissionais docentes e as circunstâncias implicadas com o campo social mediático.

Palavras-chave: comunicação, educação, marcadores profissionais, ambientes mediáticos.
Abstract: This essay continues to spread and systematize new data collected in the research conducted between 2006 and 2009 with fundamental and medium term teachers from public schools in the city and state of São Paulo. The intent, now, is to question about the tensions that surround the relationship between teacher's professional practice and actual circumstances of the social media field.

Keywords: communication, education, professional indicators, mediated environment.

Existem várias maneiras de trabalhar os vínculos da comunicação com a educação. Há o plano epistemológico voltado a indagar acerca de possível novo campo reflexivo e interventivo resultante dos encontros, desencontros, tensões, entre os processos comunicacionais e a educação. Esta, em particular, sobretudo quando pensada em sua dimensão formal, vivendo o permanente desafio representado pelas TICs, pelas intercorrências das culturas mediáticas, pelas novas maneiras de os sujeitos serem e estarem no mundo.

Podemos agregar a esse vetor de caráter epistêmico uma série de outros afeitos, por exemplo, as relações media-escola, a alfabetização para a comunicação, a leitura crítica dos meios e os estatutos que animam as relações ensino-aprendizagem promovidas, agora, por novos dispositivos de produção, circulação e recepção do conhecimento e da informação.

O fato de identificarmos, sumariamente, a existência de várias entradas para se discutir os nexos comunicação e educação evidencia a crescente importância do assunto, no mais, reconhecido pela Universidade de São Paulo, que criou, 
da formação dos jovens professores. Comunicação \& Educação. São Paulo: CCA-ECA-USP/ Paulinas, ano $X V, n$. 1 , jan./abr. 2010. Conquanto destacando aspectos diferentes, os dois textos se interpenetram podendo ser pensados no interior de uma mesma unidade analítica.

** Autor de vários artigos e livros; dentre estes: Linguagem e persuasão (Ática, 1994); Comunicação e educação: a linguagem em movimento (SENAC, 2000); Palavras meios de comunicação e educação (Cortez, 2006).

1. CITELLI, Adilson. Linguagens da comunicação e desafios educacionais: o problema da formação dos jovens professores. Comunicação \& Educação, São Paulo: CCA-ECA-USP/Paulinas, ano XV, n. 1, jan./abr. 2010. no final de 2009, junto ao Departamento de Comunicações e Artes da Escola de Comunicações e Artes, uma Licenciatura em Educomunicação.

É revelador que se tenha optado por um programa de Licenciatura, cujo foco decisivo é formar profissionais, dentre eles os professores, para atuarem nas interfaces concernentes aos temas comunicativo-educativos, estejam eles presentes no universo da escola, em sistemas informais ou não formais, nas ONGs, nos espaços mediáticos, enfim, nas várias instâncias da sociedade.

Como indicou Citelli ${ }^{1}$, as licenciaturas são, ainda, concebidas segundo uma estrutura segmentada e têm por objetivo promover competências docentes em condições de responder às solicitações disciplinares que constituem os currículos do ciclo básico continuado. Ao futuro professor de Português, Inglês, Matemática, História etc. caberá promover dinâmicas didáticas e pedagógicas - a serem estudadas e/ou apreendidas nas chamadas matérias de Licenciatura, a exemplo de Prática de Ensino, Didática - que mais bem coloquem em circulação os tópicos e conteúdos dispostos ao longo dos cursos de graduação. Tal estratégia, segmentada entre as disciplinas que formam o professor ou preparam os especialistas e as que ensinam a dar aulas, acompanha várias instituições de Ensino Superior. Daí a existência de Departamentos ou Faculdades/Institutos responsáveis por ministrar os conteúdos formativos - de História, Letras, Matemática -, enquanto outros, como a Educação, concentram as Licenciaturas. Agregue-se que estas considerações acerca da divisão social do conhecimento têm caráter geral e miram práticas e conceitos dominantes no sistema superior brasileiro. Novos modelos foram ou estão sendo estruturados e pensam a Licenciatura como integrada a um corpo formativo que não se estabelece apenas como espécie de apêndice voltada a capacitar bacharéis para se tornarem professores.

Tal matriz organizativa evidencia várias descontinuidades: tanto as graduações são arranjadas, muitas vezes, em disciplinas nem sempre conectadas entre si, como os movimentos teórico-práticos (pensando diretamente a formação para o magistério) podem acontecer segundo instâncias e até locais diferentes - a graduação é realizada na ala norte do campus e a licenciatura, na sul.

A intermitência apontada ganha outras dinâmicas e, de certo modo, amplitude quando o jovem docente passa a trabalhar no Ensino Fundamental e Médio. Agora, o cenário é marcado por uma realidade disciplinar ainda mais difusa, pois composta por grades curriculares de pequeno ou nenhum fluxo interno, fechadas por imperativos burocráticos que determinam o que pode ou não ser ministrado. Do seu lado, as disciplinas lembram ilhas atravessadas por tópicos que funcionam, muitas vezes, como se fossem pontes incapazes de suportar o peso do que deveriam transportar.

Conquanto não se busque atribuir todos os males da educação às estruturas curriculares e às dinâmicas formativas dos professores, certamente reside, aqui, uma intercorrência importante, sobretudo tendo em vista o interesse deste artigo, dirigido ao campo da educomunicação. E, nesta variável, promoveremos recorte analítico para considerar algumas dificuldades presentes no percurso de formação profissional para o magistério, quando entra em cena a questão comunicacional. 
O termo "alheamento" talvez consiga sintetizar uma das facetas que orientam as relações da educação com a comunicação. Retomássemos observações feitas em parágrafos anteriores, veríamos que o futuro professor continua, nos cursos de graduação, diante de um currículo dirigido à especialização em determinada área do conhecimento, assim como de uma licenciatura cujo alcance visível é o de ativar competências específicas para o exercício proficiente, em sala de aula, de algumas das disciplinas componentes da grade curricular. Vale dizer, a despeito dos novos paradigmas sociotécnicos, da ambiência mediática, da presença dos nativos digitais ${ }^{2}$, de formas de sensibilidade e sociabilidade orientadas por outras percepções dos vínculos entre tempo e espaço, os programas de formação para o magistério tendem a permanecer amarrados a outros contornos epistemológicos, certamente de extrema importância - não se trata, aqui, de suscitar escalas de valor, tampouco promover anteposições ou posposições ingênuas entre o céu da novidade e o inferno da tradição - em suas singularidades, mas insuficientes para abranger demandas, expectativas, contradições, jogos de linguagem, operações de acobertamentos e revelações, que a amplitude da comunicação oferece à vida social. Este é o ponto: a comunicação transformou-se em dimensão estratégica para o entendimento da produção, circulação e recepção dos bens simbólicos, dos conjuntos representativos, dos impactos materiais - afinal estamos falando, também, de uma indústria que faz computadores, vende celulares, televisores de alta definição etc.

Tal conjunto de sistemas e processos está provocando profundas transformações sociais, de algum modo promovendo impactos diretamente na vida dos homens e mulheres do nosso tempo, quer velando, quer revelando ou desvelando informações e conhecimentos.

À totalidade desses circuitos de retroalimentação envolvendo desde o plano da produção material, passando pelas estratégias de composição e circulação das mensagens, chegando aos jogos coenunciativos, podemos chamar de ecossistema comunicativo - conceito utilizado, em sentido próximo, por autores como Mario Kaplún, Jesús Martín-Barbero, Pierre Lévy, Adilson Citelli e Ismar de Oliveira Soares ${ }^{3}$. Entenda-se pelas expressões coenunciativo/coenunciação/ coenunciador designadores postos em lugar de recepção/receptor - originadas nas teorias informacionais - e que pretendem evidenciar a ideia segundo a qual a comunicação só ganha completude quando os campos de sentidos colocados em circulação social são apreendidos, tornando possível aos agentes implicados no processo constituir fluxos de mensagens.

É pertinente, no interior deste quadro, invocar o termo alheamento como indicador semântico de um estado de coisas em que a comunicação, malgrado a sua importância e significado no mundo contemporâneo, fica alijada, seja dos cursos de graduação, seja das respectivas licenciaturas. E isto, sob certo ângulo, circunscreve e mesmo reduz o conceito de educação formal a um entendimento e a uma prática pouco coetâneos, conservando as estruturas curriculares distantes de uma série de temas e problemas postos no interior do ecossistema comunicativo.
2. Expressão utilizada por Marc Prensky para designar aqueles que nasceram sob o signo da revolução informacional, telemática, sendo por ela embalados. Ao contrário, os migrantes digitais, herdeiros da sociedade industrial, têm que se adaptar aos novos paradigmas sociotécnicos. PRENSKY, Marc. Don't bother me, mom. I'm learning (Não me aborreça, mãe. Estou estudando). St. Paul: Minnesota: Paragon House, 2006.

3. KAPLÚN, Mario. Processos educativos e canais de comunicação. Comunicação \& Educação, São Paulo: CCA-USP-Moderna, n. 14, jan./abr. 1999; LÉVY, Pierre. As tecnologias da inteligência. Rio de Janeiro: Editora 34, 1995; MARTÍN-BARBERO, Jesús. Dos meios às mediações. 2. ed. Rio de Janeiro: Ed. UFRJ, 2001; Ensanchando territorios en comunicación/educación (Estendendo territórios em comunicação/educação). In: VALDERRAMA, Carlos, Comunicación \& Educación, Bogotá: Universidad Central, 2000; Heredando el futuro. Pensar la educación desde la comunicación (Herdando o futuro: pensar a educação a partir da comunicação). Revista Nómadas, Bogotá: Diuc, 1995; CITELLI, A. O. Educação e mudanças: novos modos de conhecer. In: CITELLI, A. O. (Coord.). Outras linguagens na escola: publicidade, cinema e TV, rádio, jogos, informática. São Paulo: Cortez, 2000. (Aprender e ensinar com textos, v. 6); SOARES, Ismar. Comunicação/educação: a emergência de um novo campo e perfil de seus profissionais. Contato, Brasília: Senado Federal, n. 2, 1999. 
De certo modo, a Licenciatura em Educomunicação busca não apenas formar um profissional educador que trabalhe de modo mais sistemático, orgânico, os temas, problemas, desafios suscitados pela comunicação em nosso tempo, mas também aponte na direção de um debate capaz de ampliar o campo de ação em que entram, no universo de nosso interesse, questões atinentes ao ensino-aprendizagem, às relações didático-pedagógicas, às formulações acerca dos currículos etc. E isto reconhecendo as contribuições a serem buscadas no domínio singular dos estudos de Educação - com suas pesquisas, procedimentos metodológicos, formulações teóricas -, cuja importância está largamente demonstrada.

Este texto pode ser pensado no interior destas preocupações voltadas a compreender os diálogos entre comunicação e educação, e será continuado por uma pequena reflexão tendo por indicadores os dados de pesquisa maior que realizamos com jovens professores e cujo exercício profissional estava sendo efetivado junto a escolas do Ensino Fundamental e Médio da cidade de São Paulo, conforme assinalado em passagem anterior.

A despeito de recortarmos uns poucos dados, é possível reconhecer e identificar o problema central que diz respeito à formação para se trabalhar com a comunicação nos ambientes educativos. Os motivos da preocupação parecem claros, afinal, os docentes continuam sendo o grande agente mediador dos nexos com os discentes, que, por seu turno, estão marcados pela sociedade da informação e da comunicação.

\section{PROPOSIÇÕES}

Os novos desafios postos à educação, graças aos modos singulares como a informação e o conhecimento são elaborados, distribuídos e socialmente intercambiados, precisam ser vistos em função do cenário que designamos de ecossistema comunicativo. Tal enunciado geral, guardadas as já referidas singularidades que circundam os campos da comunicação e da educação, está em Paulo Freire: "A educação é comunicação, é diálogo, na medida em que não é transferência de saber, mas um encontro de sujeitos interlocutores que buscam a significação do significado"4.

Certamente, o substantivo comunicação não aparece, aqui, como sinônimo imediato de media, tampouco a educação pode ser remetida ao território do enciclopedismo conteudístico, do monologismo professoral, dos limites formais, muitas vezes, associados ao termo. O encontro da comunicação com a educação, escoimadas, de um lado, dos desvios tecnofuncionais e, de outro, das reduções operativas e reguladoras tão presentes em procedimentos estritamente transmissivos, pode acontecer segundo andamentos dialógicos que desencadeiam as relações intersubjetivas e os jogos coenunciativos. É deste encontro de sujeitos à busca da significação do significado, momento particular de ativação dos princípios da reciprocidade, ou da retroalimentação, que os atos comunicativos ganham efetividade, conquanto sustentados por mediadores técnicos ou dispositivos amplificadores do que está sendo enunciado. 
Indicados, sinteticamente, os lineamentos que orientam de maneira mais profícua as interfaces comunicação/educação, é pertinente desdobrar a análise indagando acerca das dinâmicas societárias e dos envolvimentos dos sujeitos que ensejam aquelas inter-relações. Ante um ambiente cultural atravessado de maneira contínua por mudanças resultantes - para restringirmos os nossos referenciais - das novas mediações tecnológicas, da apreensão cronotópica forjada pelos ritmos do tempo acelerado e do espaço contraído, pelos trânsitos, muitas vezes imperceptíveis, envolvendo ocorrência, presencialidade, virtualidade, se torna imperioso propor o estreitamento das passagens entre novos sensórios: educação e comunicação.

É pertinente lembrar que as grandes mudanças tecnológicas sempre solicitaram outros padrões educativos. Já no Manifesto do Partido Comunista, de 1848, Marx e Engels mostravam como as modificações nos instrumentos de produção provocavam alterações nas relações de produção e nas demais relações sociais. "A burguesia não pode existir sem revolucionar continuamente os instrumentos de produção, portanto as relações de produção e, assim, o conjunto das relações sociais"

Falamos, contudo, agora, de um gigantesco movimento no interior do qual a comunicação, em suas múltiplas formas, conceitos, manifestações, passa a desempenhar papel de centralidade, de locus estratégico. Tal fenômeno vem sendo tratado, sob diferentes perspectivas, registros e compreensões teóricas, por formulações como O príncipe eletrônico (Octávio Ianni), Mediatização generalizada (Fausto Neto, Muniz Sodré), Hipermediatização da sociedade (Eliseo Veron) ${ }^{6}$, Ecossistema comunicacional (autores já indicados), para nos limitarmos a alguns dos designadores situados semanticamente nesta área de reconhecimento do lugar determinante que os sistemas e processos comunicacionais ganharam na contemporaneidade.

Ainda que não seja o lugar, aqui, de explorar as bases teóricas presentes naquelas categorias - algumas com fortes contornos políticos e ideológicos -, nomeá-las faculta vislumbrar um esforço reflexivo para situar a força de um fenômeno em andamento e de reconhecidas implicações econômicas, sociais e culturais. Neste contexto são compreensíveis os motivos que levaram alguns programas de Licenciatura, de cursos de formação de professores, de áreas de Pedagogia, a incluírem em suas grades curriculares, ainda que, muitas vezes, de maneira desordenada, difusa, incompleta, tímida, disciplinas com o título de: Mídia e educação, Educação para a mídia, Comunicação, educação e multimídia, Meios de comunicaşão em educação, Comunicação educativa, Comunicaşão, educação e tecnologias, Educação e novas tecnologias da educação.

Identificamos tais disciplinas, como partes de um conjunto de outras, consultando trinta e quatro instituições de Ensino Superior no País, basicamente entre Faculdades de Educação, pois elas costumam ser as principais responsáveis por ministrar os programas de Licenciatura $(2009)^{7}$. Deste grupo, oito não forneciam matérias no âmbito de nosso interesse, dez deixaram de repassar os currículos solicitados e dezesseis apresentaram alguma disciplina, como as referidas acima, voltadas ao campo da comunicação.
5. Edição especial do Manifesto. MARX, Karl; ENGELS, Frederich. Manifesto do Partido Comunista. Edição especial traduzida por Marcus Vinicius Mazzari. Revista Estudos Avançados, São Paulo: USP, n. 34 , p. 10 , 1998.

6. IANNI, Otávio. O príncipe eletrônico. In: BACCEGA, Maria Aparecida (Org.). Gestão de Processos Comunicacionais. São Paulo: Atlas, 2002; FAUSTO NETO, Antônio. Midiatização: prática social - prática de sentido. In: SEMINÁRIO MEDIATIZAÇÃO, 2006, Bogotá. [Paper] Bogotá, 2006; SODRÉ, Muniz. Eticidade, campo comunicacional e midiatização. In: MORAES, Denis. Sociedade midiatizada. Rio de Janeiro: Mauad, 2006; VERÓN, Eliséo. Esquema para el análisis de la mediatización (Esquema para a análise da mediatização). Diálogos de la Comunicación, Lima, n. 48, out. 1997.

7. CITELLI, Adilson. Linguagens da comunicação e desafios educacionais: formação de jovens professores e circunstâncias mediáticas (1996-2005). Relatório de pesquisa. CNPq, 2009. Posse do autor. 
A pergunta atinente à estrutura curricular das instituições de Ensino Superior fazia parte da nossa citada pesquisa realizada com 79 professores do Ensino Fundamental e Médio, com idade máxima de 30 anos, quando da efetivação da enquete, pertencentes à rede pública de São Paulo, incluindo escolas estaduais e municipais. E desejávamos saber, em determinado segmento da investigação, se os docentes haviam tido, ao longo dos seus cursos, contato com matérias afeitas de modo direto à área da comunicação.

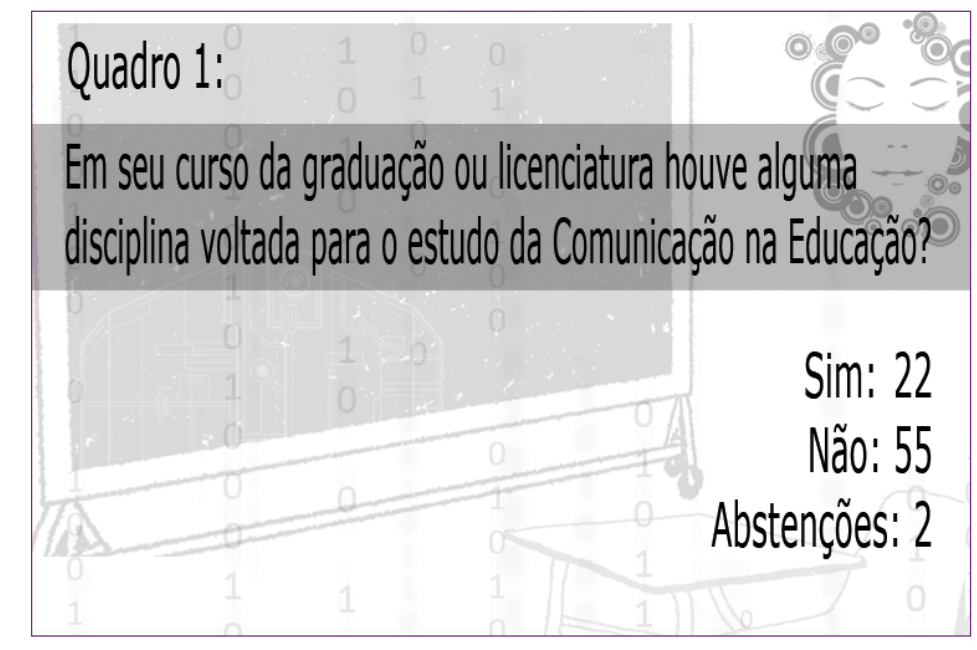

O quadro, já presente em artigo de Citelli $(2010)^{8}$, mas posto aqui sob outra inflexão analítica, esclarece um dos problemas centrais com o qual nos debatemos, quando se trata de observar a presença da comunicação nos ambientes escolares: a própria formação do docente que irá atuar em sala de aula e que encontrará os discentes nativos digitais, referidos por Marc Prensky. A tabela indica que apenas 22 dentre os 79 professores pesquisados cursaram alguma disciplina capaz de mais bem capacitá-los para trabalhar com a comunicação (ou mesmo os media) em sala de aula. Após vários anos realizando pesquisas nesta área e repetindo, praticamente, esta mesma pergunta, constatamos pouca mudança, conquanto houvéssemos fixado, agora, um segmento etário circundado cotidianamente pelo já mencionado locus estratégico. É pertinente afirmar que muitas das licenciaturas existentes no País prosseguem dispensando nenhuma ou discretíssima atenção a um evento fundamental para se pensar nas dinâmicas das sociedades contemporâneas: os meios de comunicação e suas linguagens.

O dado relevante e ao mesmo tempo paradoxal é que os docentes com os quais fizemos a nossa pesquisa aumentaram de modo significativo o acesso aos recursos mediáticos. Indagamos acerca da frequência à televisão, ao rádio, à leitura de jornais e revistas; acesso à internet. Enfim, existiu o intuito de saber como o docente age enquanto usuário dos media. Afinal, essa ambiência referencia um dos cenários nos quais são elaborados não apenas perfis profissionais,

8. Id. Linguagens da comunicação e desafios educacionais..., cit. mas também formas de vida, interesses particulares, fontes de informações, redes de sociabilidades etc. Vale dizer, entre salas de aula, telas de computador, programas de rádio ou televisão, os sujeitos deslocam-se em dupla posição: ao 
mesmo tempo estão envolvidos com o universo escolar - são os professores, equipes de apoio, diretores - e incluídos na sociedade mais ampla, na qual desempenham papéis de pais, afiliados a igrejas ou partidos, participantes de equipes de futebol, animadores de festas, expectadores de filmes, fãs de música etc. Há sujeitos empenhados quer em projetos político-pedagógicos das escolas, com a formação dos jovens que viverão a complexidade da polis, quer em ser desafiados a negociar com as variadas dimensões operacionais e de linguagem disponibilizadas pelos meios de comunicação.

Um exame nos dados da pesquisa feita por Citelli $(2009)^{9}$, alguns deles discutidos em artigo do mesmo autor $(2010)^{10}$, demonstra como os jovens docentes aumentaram expressivamente o acesso aos equipamentos digitais: $87 \%$ deles asseguram ter computador, contra os 40\% revelados em números de 1996. Daquele grupo, mais de $80 \%$ possui conexão com a internet.

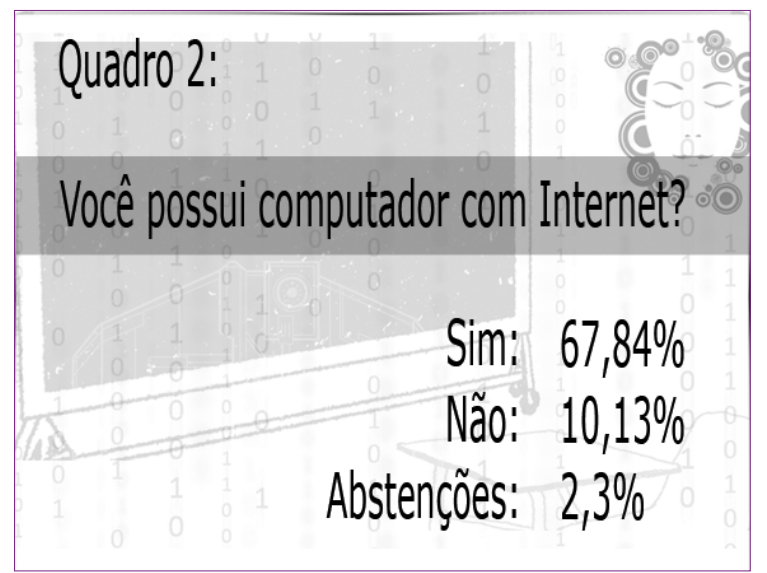

Apenas para fixar alguns tópicos atinentes aos usos dos recursos digitais, percebe-se que os professores - ao menos o grupo objeto de nossa pesquisa, mas que, de certo modo, é revelador de conjunto maior que leciona na cidade de São Paulo - participam do crescente acesso às tecnologias digitais.

Ampliando o escopo destas constatações, é possível observar que as próprias unidades escolares nas quais atua o nosso grupo de professores têm recursos tecnológicos que as colocariam em certa sintonia com o que alguns autores vêm chamando de cultura das mídias. Certamente não se está, aqui, afirmando haver nas escolas um ambiente educativo favorável à efetivação de projetos político-pedagógicos voltados à formação plena dos alunos - no que se inclui a alfabetização para mais bem compreender o papel e as determinações envolvidas com os meios de comunicação -, tampouco se proclama existir correlação imediata entre computadores, equipamentos de rádio, internet e a melhoria na qualidade de ensino. Ao contrário, o que se encontra em sala de aula é, muitas vezes, um sistema em crise, com enorme quantidade de problemas, e que não consegue cumprir o seu objetivo fim: promover ensino de qualidade aos estudantes.

De toda sorte, voltemos aos dados da pesquisa, recolhendo alguns indicadores da presença dos dispositivos técnicos nas escolas.
9. CITELLI, Relatório de pesquisa..., cit.

10. Id. Linguagens da comunicação e desafios educacionais..., cit. 
comunicação \& educação • Ano XV • número 2 • maio/ago 2010

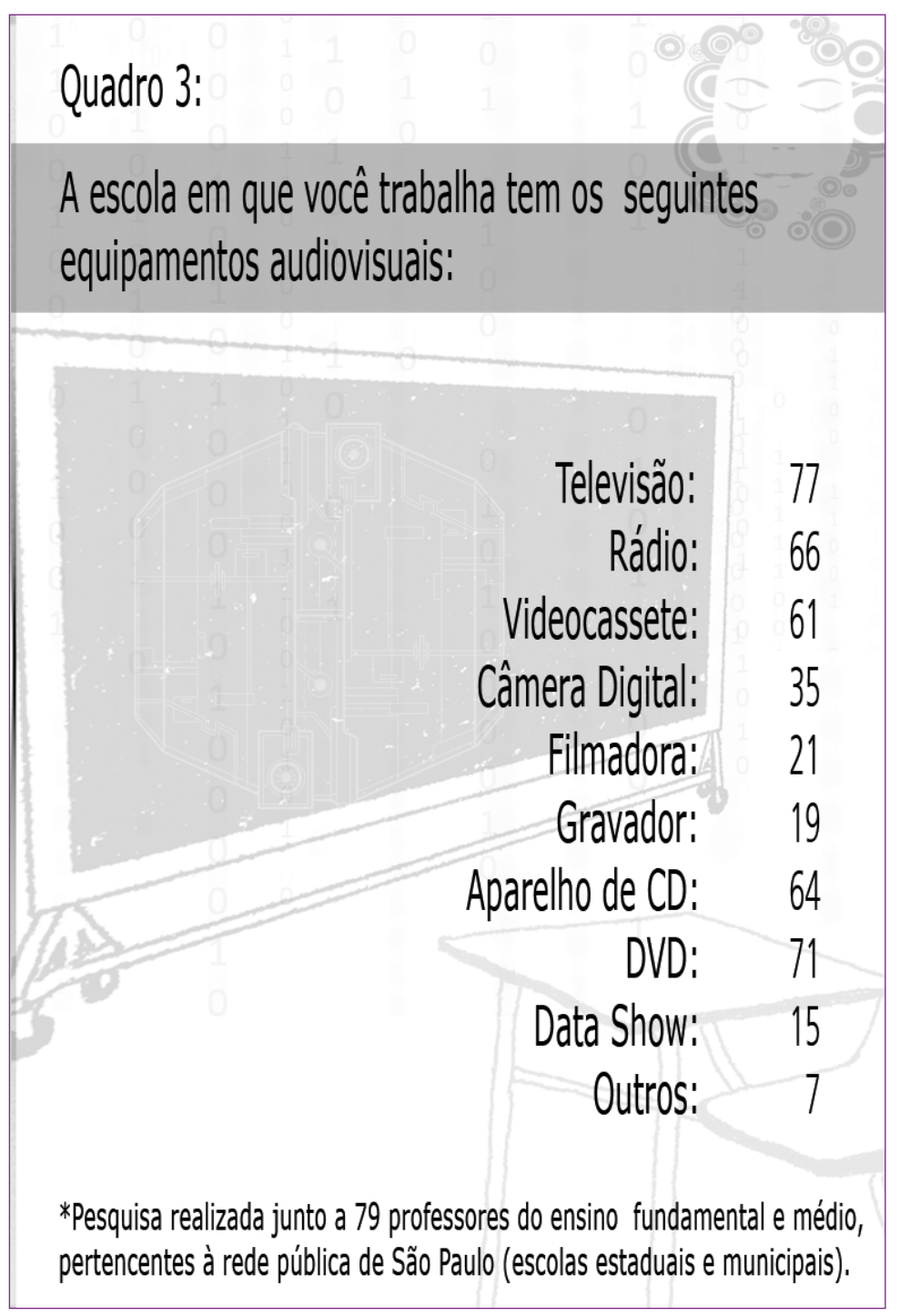

Nos últimos anos as escolas vêm se equipando dos recursos audiovisuais. Itens como televisão, DVD, rádio, aparelhos de $\mathrm{CD}$ estão presentes em praticamente toda a rede de ensino pública, o que representa uma tentativa de acompanhar a celeridade das mudanças ocorridas no âmbito das tecnologias audiovisuais.

É oportuno observar que a escola enfrenta, no afeito às relações com os recursos técnicos, uma situação complexa. Ao mesmo tempo existe o apelo à modernização (entendendo, aqui, o limite do termo no âmbito da questão objeto do comentário) e as armadilhas de uma lógica produtiva baseada no efêmero. A retórica acerca da necessidade de se acompanhar as mudanças tecnológicas é procedida por outra retórica ainda mais agressiva e justificadora in limine daquela necessidade. O círculo de giz caucasiano não se fecha. A indústria opera em duas frentes, a dos valores simbólicos - é imperioso acompanhar a última palavra em inovação tecnológica - e a das mudanças de padrão (upgrades, design, novas linhas de produtos etc.), que tornam superados, em curto tempo, equipamentos relativamente novos. 
A tal lógica perversa, o Estado deve responder com o aporte de volumosos recursos, modernizando a escola, acedendo aos apelos, muitas vezes, nascidos de formadores de opinião ou grupos de pressão com vínculos junto à indústria. A espiral das demandas por suportes para alcançar-se, em tese, aulas mais qualificadas e melhores padrões de ensino parece criar a sua própria rotina; há um moto próprio regendo o discurso pela sala de aula com maior quantidade de equipamentos tecnológicos de última geração.

Verificando os dados anteriores, deparamo-nos, imediatamente, com um exemplo do que se poderia chamar expressões do efêmero: os videocassetes, que tiveram a duração de um veranico e compuseram um dos vértices fundamentais do projeto da TV Escola. Ou seja, um importante programa do Governo Federal, nos inícios dos anos 1990, voltado à educação a distância dos professores, com o intuito de alcançar as mais de 50 mil escolas brasileiras, com seus aproximados um milhão de professores, ficou rapidamente comprometido por uma repentina mudança no padrão tecnológico, agora sustentado pelo DVD. Entende-se o motivo de as escolas que pesquisamos registrarem número maior destes aparelhos (71), contra 61 videocassetes, a despeito do tempo relativamente curto de passagem de um a outro suporte.

Ao lado do DVD começa a temporada de sucesso de outro equipamento, o data show. Ainda ausente nas pesquisas que promovemos entre o final de 2001 e início de 2002, com um universo de 220 professores da rede pública do Estado de São Paulo, surge, agora, em 15 das 79 escolas acerca das quais fazemos referência neste texto.

Para efeito comparativo, segue tabela referente a 2001/2002:

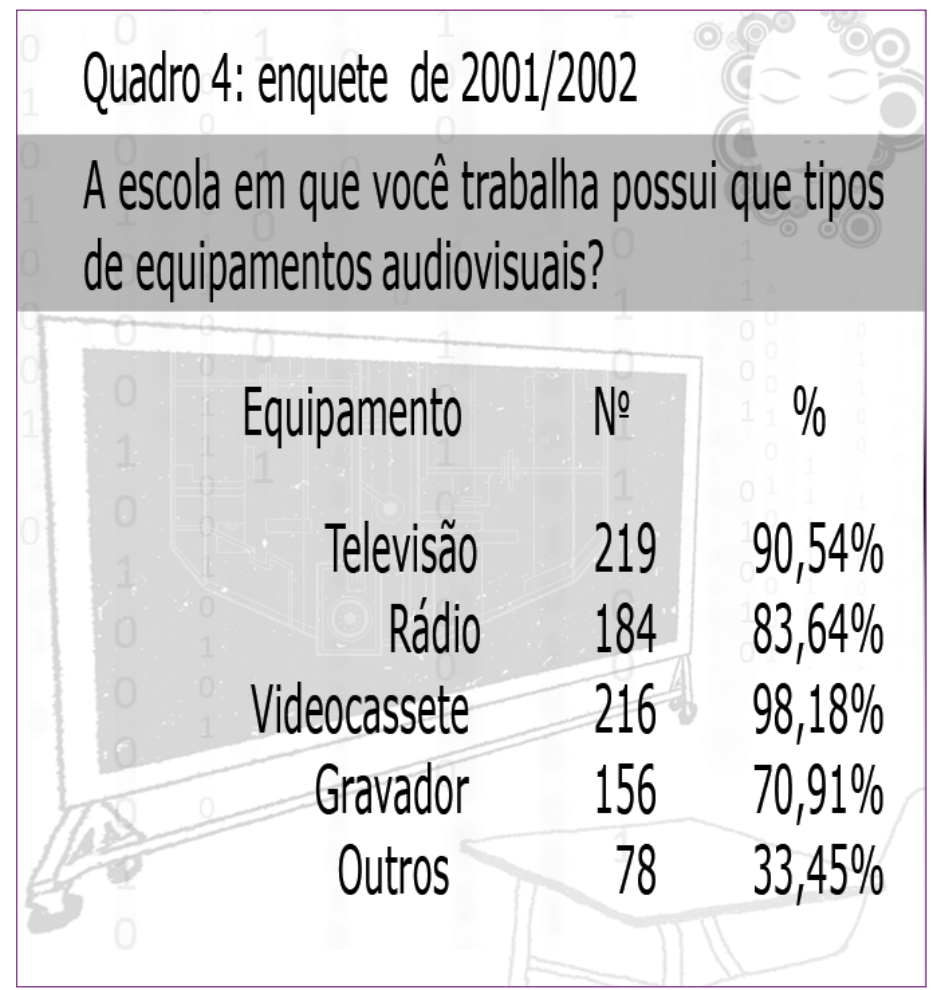


comunicação \& educação • Ano XV • número 2 • maio/ago 2010

Ou seja, não apenas diminui a indicação do videocassete, agora citado em $77,21 \%$ das escolas, como aparecem em números significativos os DVDs $(89,87 \%)$ e em menor escala os data shows $(18,98 \%)$.

De toda maneira e retomando os dados de nossa pesquisa atual, verifica-se que alguns equipamentos de possível utilização pelos docentes podem ser encontrados na maioria das instituições educativas vinculadas aos entrevistados.

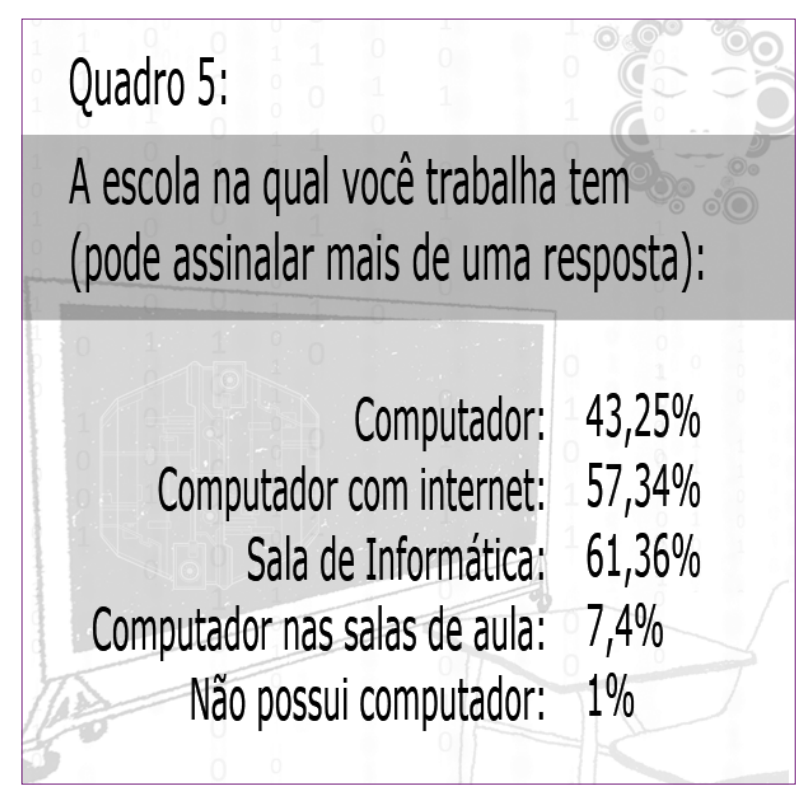

Esta questão visava registrar de modo um pouco mais detalhado como o computador se apresenta na escola. Considerando os vários cruzamentos permitidos pelo item (inclusive aquele que indica a posse de computadores e acesso à internet por parte dos professores), reconhece-se que praticamente todas as unidades de ensino têm o equipamento.

E apenas para ampliar um pouco este quadro, trazemos à cena a variável dos alunos.

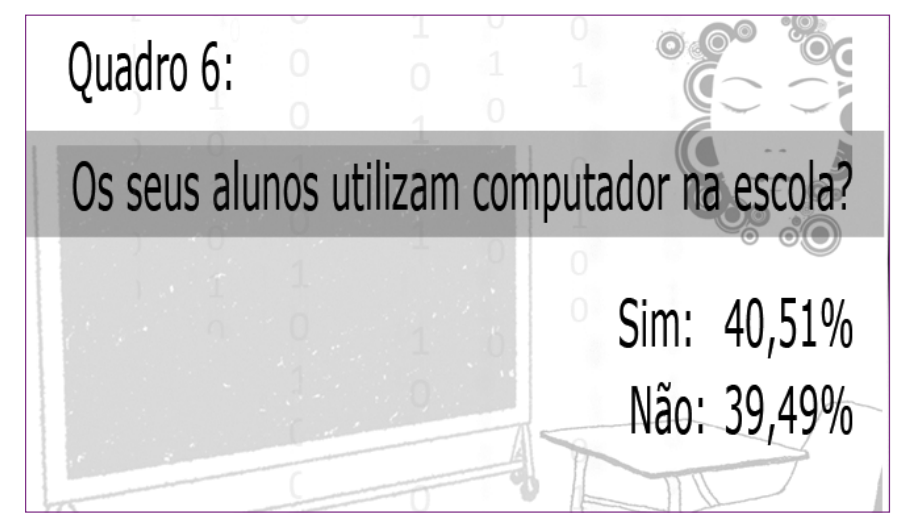

As respostas dos professores revelam existir divisão praticamente ao meio entre alunos que utilizam computadores e os que não o utilizam no espaço escolar. É difícil avaliar, pelas próprias condições estruturais em que se processa 


\section{Comunicação e educação • Adilson Citelli}

o trabalho didático-pedagógico na rede pública, o significado real de quase metade dos alunos não fazerem uso dos equipamentos que existem na maioria das escolas. Sabemos das limitações, muitas vezes, motivadas por problemas de segurança, outras por óbices decorrentes das dinâmicas funcionais. De todo modo, a maioria das escolas a que estamos nos referindo mantém suas salas de informática em funcionamento.

Avaliação mais consistente desta questão pediria pesquisa detida com os alunos, mecanismo através do qual seria possível indagar dos motivos pelos quais os discentes usam ou não os equipamentos de informática disponibilizados pela escola.

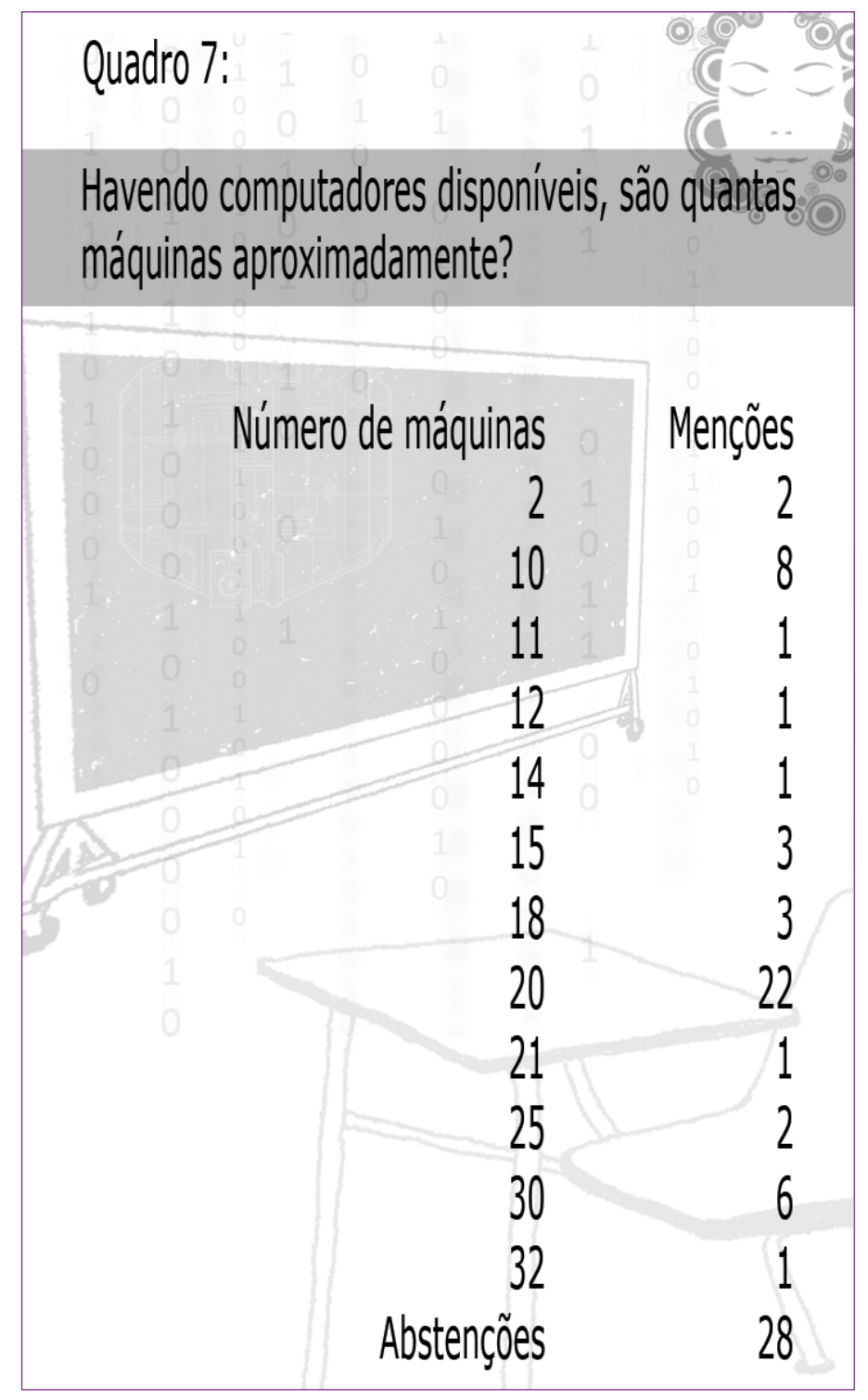

Do conjunto de questões referentes à presença do computador na escola, esta nos ajuda a aproximarmos um pouco mais do problema. Considerando que $28(35,44 \%)$ dos professores se abstiveram neste item e que, portanto, 
comunicação \& educação • Ano XV • número 2 • maio/ago 2010

trabalhamos com um universo de $51(64,55 \%)$, verificamos um quadro diferente entre as unidades referidas. Desde menções à existência de 2 até 32 máquinas. Vale dizer, o fato de as escolas possuírem computadores não significa dizer que haja equipamentos em quantidade suficiente para atender à demanda.

Note-se que a variação entre 2 e 32 máquinas é significativa. O número de 20, o mais citado pelos docentes (22), fica muito aquém do necessário para os alunos realizarem de maneira profícua atividades continuadas que tenham por suporte o computador. É preciso acrescentar, e apenas para efeito de cálculo, que falamos da existência média de 485 alunos por turno, somados todos os discentes e divididos pelo número de escolas alcançadas pela nossa pesquisa.

\section{UMA SÍNTESE}

Neste recorte de dados, com certa ênfase final na questão do uso dos computadores, é possível apurar que tanto os professores como os seus alunos circulam em território marcado pelos diversos dispositivos comunicacionais. De maneira meio acelerada, de forma mais ou menos procedente, o mundo da escola registra crescente aproximação às novas tecnologias e às linguagens postas em circulação, mesmo pelos media tradicionais como rádio, jornal, televisão.

Isto nos reenvia ao quadro 1, referente à formação do professor para trabalhar com as questões da comunicação na educação. Ou seja, existe certa descontinuidade entre demandas de alunos, escolas e dos próprios docentes - já integrados ao amplo processo de mediatização -, e procedimentos formativos capazes de mais bem responder, no plano didático-pedagógico, a tal cenário das práticas educativas em sala de aula. É como se estivéssemos diante de duas realidades distintas: uma representada pelos envolvimentos sociais com os sistemas e processos da comunicação e outra adstrita a determinados marcos institucionais que balizam e circunscrevem o mundo da escola. Caberia, aqui, perguntar:

[...] o fato de existirem novas sociabilidades, nexos quase naturalizados entre o sujeito e os diferentes suportes tecnocomunicacionais teria permitido alcançar a atividade profissional do futuro docente, ele próprio formador de outros tantos jovens, ainda mais afeitos aos lineamentos da ampla mediatização? Na eventualidade de os professores licenciados em anos recentes haverem recebido formação adequada para trabalhar neste ambiente, estariam eles ressignificando em sala de aula os temas, problemas, propostas de linguagens, contornos estéticos etc., postos em circulação pelas culturas mediáticas, mas, segundo uma perspectiva educacional e pedagogicamente equacionada aos ditames da escola, aos propósitos que devem reger a construção de uma cidadania transformadora, crítica e competente para enfrentar os desafios que esperam os discentes ${ }^{11}$ ?

Pelo que verificamos, a convivência e/ou familiaridade maior com os

11. CITELLI, Adilson. Linguagens da comunicação e desafios educacionais..., cit. computadores, a internet, os aparelhos de televisão digital não se integra, necessariamente, nos projetos ensejados nas instituições destinadas à formação dos professores, tampouco nas práticas por estes levadas a termo nas salas de 
aula do Ensino Básico. O saldo final do desajuste tem representado importante fonte geradora - conquanto não sendo, evidentemente, a única - de problemas que alcançam, hoje, uma parte da educação formal no Brasil.

\section{CONCLUSÕES}

Caso agregássemos às observações anteriores alguns outros vetores da pesquisa realizada - e que não cabem ser retomados no momento -, encontraríamos vários desencontros que circundam as subculturas escolares, tanto no que diz respeito à formação inicial dos professores como nas práticas por eles implementadas em suas salas de aula, sempre tendo por horizonte as interfaces envolvendo comunicação e educação.

Vimos colocando tais desencontros à luz da tensão entre o circunscrito e o expandido, com os óbvios entrecruzamentos e interdependências aí presentes. De um lado, a escola e o seu discurso canônico, ritualístico, ao mesmo tempo ordenador e normalizado, e, de outro, os meios de comunicação e as próprias dinâmicas da vida cotidiana em sua dispersão temática, pluralidade de ofertas informativas e multiplicidade de linguagens.

Enunciando o problema em outros termos: as práticas em sala de aula costumam imbricar valores e referências instruídas por expectativas enciclopédias, propedêuticas, nem sempre equacionadas aos requisitos dos alunos ou mesmo das dinâmicas sociais, de certo modo enquadrando ou reduzindo para aumentar planos de controle, articular consensos e promover hegemonias. Por sua vez, os media, em luta permanente para constituir campos de dominância, parecem completar supostas ou reais faltas da escola, apresentando-se como um outro meio pleno de sedução e capacidade de acenar com informações aparentemente suficientes para dispensar agências que lhes possam fazer concorrência no mister de arrolar dados, predicar comportamentos, elaborar explicações, narrar toda sorte de acontecimentos.

É neste panorama, amplamente vinculado aos dispositivos mediáticos, que o jovem docente cumpre a chamada formação inicial, requisito para seguir em uma carreira cujo objetivo último é promover educação de qualidade e compromissada com os imperativos da cidadania. Tal perspectiva desafiadora deve atentar, agora, para o que designamos como dinâmicas expansivas - nas quais os dispositivos comunicacionais registram presença de conhecida relevância. Afinal, daqui derivam novas sensibilidades e sociabilidades, em que se constituem os sujeitos/agentes - conceito de Alain Tourraine referente à possibilidade de alterar o plano material e social em que o sujeito se localiza, impactando, deste modo, na divisão do trabalho, nas tomadas de decisão, nas dinâmicas culturais. O pensador francês entende que resulta das relações entre sujeitos o fato de os indivíduos deixarem de "ser um elemento do funcionamento do sistema social para retornarem como criadores de si mesmos e produtores da sociedade" ${ }^{12}$. Noutras palavras: o sujeito/agente e não o indivíduo manifesta força transformadora/construtora da cidadania.
12. TOURRAINE, Alain. Crítica da modernidade. Lisboa: Piaget, 1992. p. 269. 
comunicação \& educação • Ano XV • número 2 • maio/ago 2010

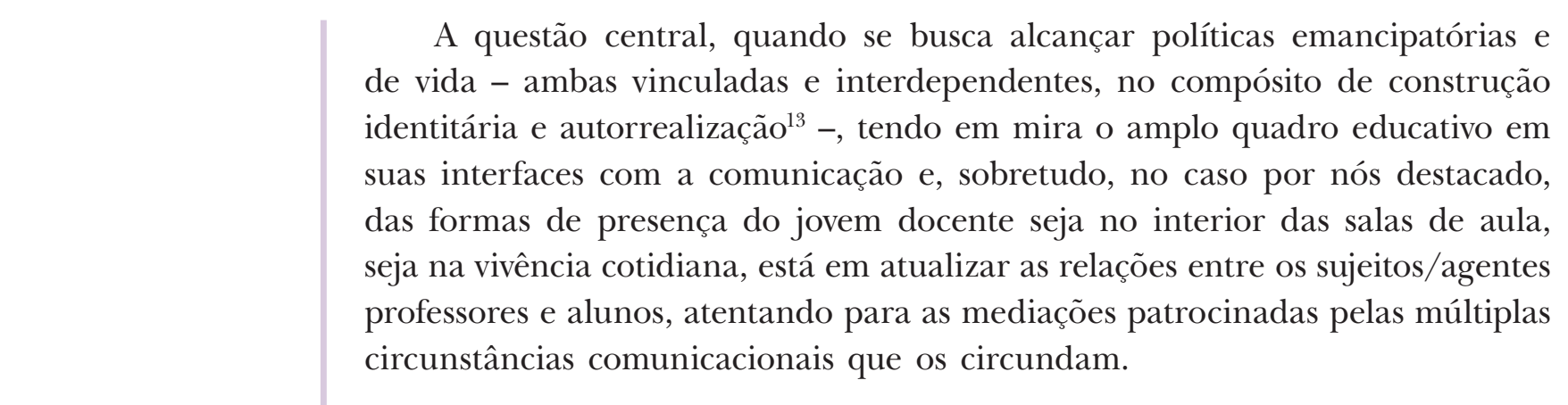

\section{REFERÊNCIAS BIBLIOGRÁFICAS}

CITELLI, Adilson. Linguagens da comunicação e desafios educacionais: o problema da formação dos jovens professores. Comunicação \& Educação, São Paulo: CCA/ECA/USP/Paulinas, ano XV, n. 1, jan./abr. 2010.

Linguagens da comunicação e desafios educacionais: formação de jovens professores e circunstâncias mediáticas (1996-2005). Relatório de pesquisa. CNPq, 2009. Posse do autor.

. Palavras, meios de comunicação e educação. São Paulo: Cortez, 2006.

(Org.). Outras linguagens na escola. São Paulo: Cortez, 2001.

Comunicação e educação: a linguagem em movimento. São Paulo: Senac, 2000.

Educação e mudanças: novos modos de conhecer. In: CITELLI, A. O. (Coord.). Outras linguagens na escola: publicidade, cinema e TV, rádio, jogos, informática. São Paulo: Cortez, 2000. (Aprender e ensinar com textos, v. 6).

FREIRE, Paulo. Extensão ou comunicação. 8. ed. Rio de Janeiro: Paz e Terra, 1985. Biblioteca digital da UFP.

GUIDENS, Antony. Modernidade e identidade. Rio de Janeiro: Zahar, 2002.

HELLER, Agnés. O quotidiano e a história. Rio de Janeiro: Paz e Terra, 1972.

13. GUIDENS, Antony. Modernidade e identidade. Rio de Janeiro: Zahar, 2002.
. A theory of modernity (A teoria da modernidade). Cambridge: Blackwell Publishers, 1994.

IANNI, Otávio. O príncipe eletrônico. In: BACCEGA, Maria Aparecida (Org.). Gestão de Processos Comunicacionais. São Paulo: Atlas, 2002.

KAPLÚN, Mario. Processos educativos e canais de comunicação. Comunicação \& Educação, São Paulo: CCA-USP-Moderna, n. 14, jan./abr. 1999.

LÉVY, Pierri. As tecnologias da inteligência. Rio de Janeiro: Editora 34, 1995.

MARTÍN-BARBERO, Jesús. Dos meios às mediações. 2. ed. Rio de Janeiro: Ed. UFRJ, 2001. 


\section{Comunicação e educação • Adilson Citelli}

Ensanchando territorios en comunicación/educación (Estendendo territórios em comunicação/educação). In:VALDERRAMA, Carlos. Comunicación \& Educación, Bogotá: Universidad Central, 2000.

Heredando el futuro. Pensar la educación desde la comunicación (Herdando o futuro: pensar a educação a partir da comunicação). Revista Nómadas, Bogotá: Diuc, 1995.

MARX, Karl; ENGELS, Frederich. Manifesto do Partido Comunista. Edição especial traduzida por Marcus Vinicius Mazzari. Revista Estudos Avançados, n. 34. São Paulo: USP, 1998.

PRENSKY, Marc. Don't bother me, mom. I'm learning (Não me aborreça, mãe. Estou estudando). St. Paul, Minnesota: Paragon House, 2006.

SOARES, Ismar. Comunicação/educação: a emergência de um novo campo e perfil de seus profissionais. Contato, Brasília: Senado Federal, n. 2, 1999.

SODRÉ, Muniz. Sobre a episteme comunicacional. Matrizes: revista de pósgraduação em Ciências da Comunicação, São Paulo: ECA/USP, 2007.

Eticidade, campo comunicacional e midiatização. In: MORAES, Denis. Sociedade midiatizada. Rio de Janeiro: Mauad, 2006.

TOURRAINE, Alain. Crítica da modernidade. Lisboa: Piaget, 1992.

VERÓN, Eliséo. Esquema para el análisis de la mediatización (Esquema para a análise da mediatização). Diálogos de la Comunicación, Lima, n. 48, out. 1997. 

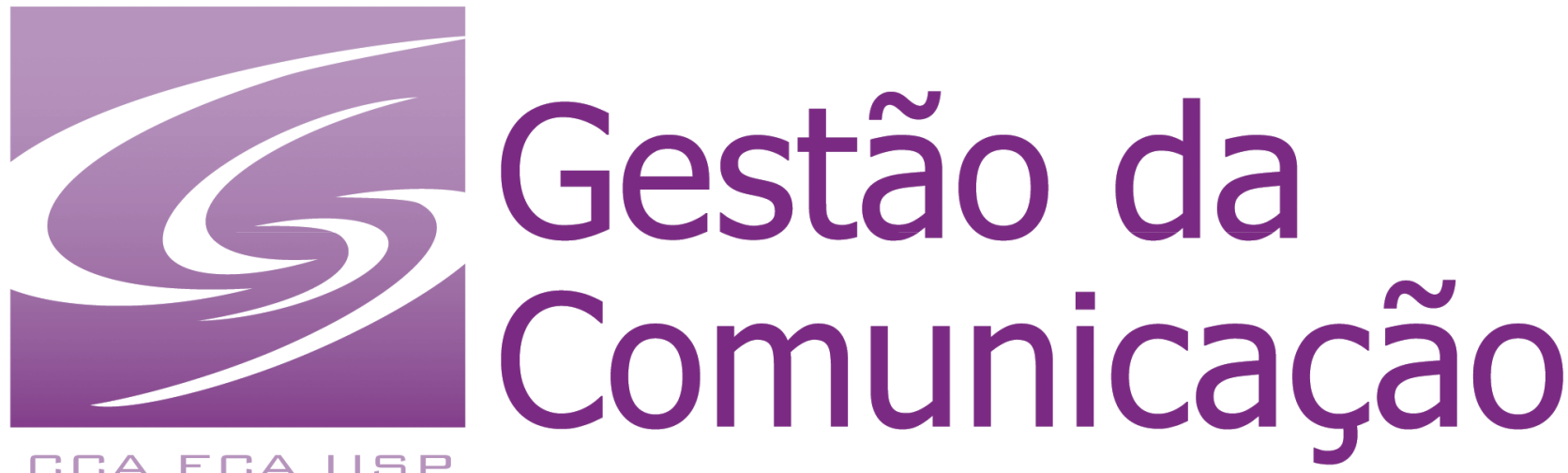

ロடA EロA பSP

\section{O mais experiente e atualizado Curso de Especialização em Comunicação da USP}

O gestor da comunicação planeja e executa projetos de comunicação em empresas privadas, instituições públicas ou movimentos comunitários nas áreas educacional, empresarial ou artístico-cultural.

três semestres

formação superior (qualquer área) prova escrita, entrevista e plano de estudo

turma com aulas de segunda a quarta-feira turma com aulas às sextas-feiras e aos sábados.
Capacitação do aluno para eleborar, implantar, avaliar e reestruturar projetos de comunicação/ cultura.

Integração teórico-prática da área de comunicação com o mercado de trabalho. Formação humanística e profissional sólidas, baseada na inter-relação comunicação/cultura/ artes.

Qualificação do profissional, preparando-o para compreender o mercado emergente, em constante transformação, e agir sobre ele. eca

usp

Departamento de

Comunicações e Artes

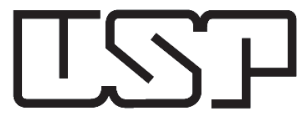

(+5511) 3091-4341

+551 1 3091-4867

www.eca.usp.br/ gestcom@usp.br
Av. Prof. Lúcio Martins

Rodrigues, 443, sl 209

Cidade Universitária São Paulo SP 